\title{
Congenital QT Syndrome Causing Syncope in Children, A Case to be proposed
}

\author{
Hicham Faliouni ${ }^{*}$ Lahlafi Zakaria, Mohammed Malki, Lakhal Zouhair
}

Service de Cardiologie, Hôpital Militaire d'Instruction Mohammed V. Université Mohammed V. Rabat, Morocco

DOI: $10.36347 /$ sjmcr.2020.v08i07.022

| Received: 16.07.2020 | Accepted: 24.07.2020 | Published: 28.07.2020

*Corresponding author: Hicham Faliouni

Abstract

Congenital long QT syndrome (SQTL) is a group of genetically heterogeneous heart diseases characterized by repolarization disorders secondary to QT prolongation, leading to an increased risk of ventricular arrhythmia. The genes involved in these mutations encode for subunits of the ion channels responsible for cardiac electrical activity. SQTL should be evoked during the onset of syncope or sudden death in young subjects in the context of adrenergic stimulation. There is often a delay in diagnosis in this age group, because the symptoms are, wrongly, attributed to an epilepsy attack. The diagnosis is based on the electrocardiogram, a family survey and a genetic study. The treatment is based on beta-blockers and the implantable defibrillator. We report through an observation of a 3 years old girl who presented loss of consciousness following exertion. We will discuss her diagnosis andtreatment.

Keywords: Congenital long QT syndrome (SQTL), heart diseases, syncope.

Copyright @ 2020: This is an open-access article distributed under the terms of the Creative Commons Attribution license which permits unrestricted use, distribution, and reproduction in any medium for non-commercial use (NonCommercial, or CC-BY-NC) provided the original author and source are credited.

\section{INTRODUCTION}

Long QT syndrome (SQTL) is a possible factor in sudden death. It is characterized by an abnormality of ventricular repolarization on the surface electrocardiogram (ECG) (elongated QTc $\geq 440 \mathrm{~ms}$ ) associated with a significant risk of syncope or sudden death due to ventricular arrhythmias of the torsade de pointes type or ventricular fibrillation.

We report the case of a girl who presented after an effort a faintness with loss of consciousness. We discuss the diagnostic means and the methods of treatment.

The interest of this observation is to insist on the need to perform an electrocardiogram for each child admitted to pediatrics or seen in consultation for illlabeled discomfort with loss of consciousness.

\section{Observation}

A little girl of consanguineous parents, born by caesarean section at 30 weeks with amenorrhea (AS). Her family's history is marked by sudden death in her older brother at the age of 3 months. She was with sensorineural hearing loss for which she had a cochlear implantation. At the age of 3 , she fainted with a discomfort after doing some effort. The immediately performed EKG shows a very long QT interval with QT corrected to 0.527 seconds (Figure-1). She was put on b-blocker therapy and drug avoidance instructions were given and she received an indwelling pacemaker implantation. Since the discomforts are no longer reproduced. The family investigation revealed an asymptomatic congenital long QT syndrome in the father.

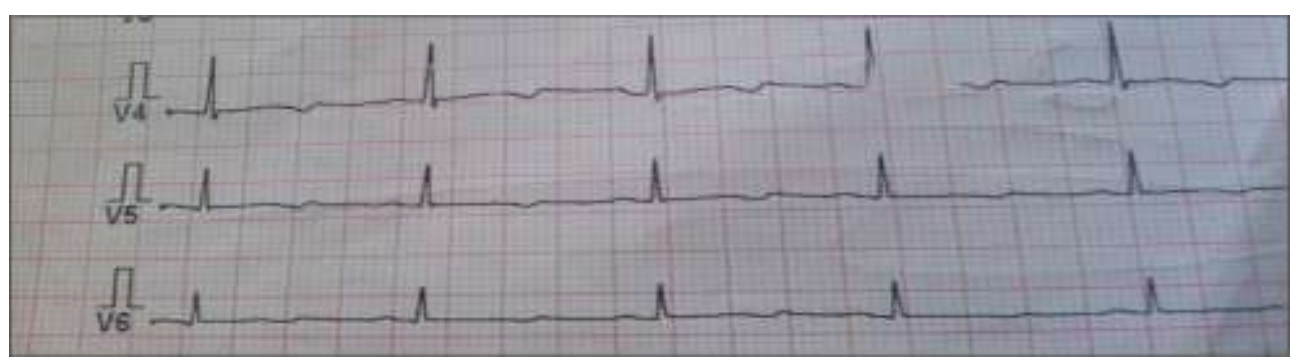

Fig-1: QTe prolonged (527 ms) 


\section{DISCUSSION}

The QTc is prolonged if it is greater than 440 $\mathrm{ms}$ in men and greater than $460 \mathrm{~ms}$ in women and children. However, a much higher QTc value is often reported in the literature, and Congenital long QT syndrome, defined by the corrected QT space (calculated according to Bazett's formula) greater than 0.44 seconds, is a rare condition.

An international multicenter study reported only 287 cases in seven countries [1]. Congenital long QT syndrome obeys two modes of transmission, a recessive mode of transmission, associated with hearing loss (Jervell-Lange-Nielsen syndrome) to which our observation corresponds and a dominant mode (Romano-Ward syndrome).

Family history and genetic origin have been known for many years. Thirteen genes encoding cardiac ion channel subunits (potassium and calcium) have been distinguished. In $75 \%$ of cases, the mutation is identified, and in $90 \%$ of cases, it is one of the following three genes: LQT1, LQT2 and LQT3 [2].

Mutations in genes coding for ion channel subunits are responsible for an increase in $\mathrm{Na}+$ and $\mathrm{Ca} 2$ + depolarizing currents, or decrease repolarizing potassium currents. The consequence is a prolongation of the ventricular action potential, resulting in a prolongation of the QT interval, which can degenerate into Torsade de Pointe. Our patient was not subjected to a genetic study.

It is usual to use Bazett's formula to correct the QT value for the heart rate $(\mathrm{QTc}=\mathrm{QT} / \sqrt{\mathrm{RR}})$. It is accepted that a threshold greater than $500 \mathrm{~ms}$ would be a factor of poor prognosis and risk of occurrence of torsade de pointes.

Clinically, these patients experience syncope triggered by exercise or intense effort, emotion, anesthesia or excessive noise. Another mode of revelation is represented by seizures, even by sudden death. In our observation, there was a sudden death in our patient's siblings. The mode of presentation was uneasiness and loss of consciousness.

Congenital long QT syndrome affects boys and girls without predilection; as in the case reported by Garson.

In the absence of secondary causes that can prolong the QT (drug, ionic), the diagnosis should be considered in the following cases:

- QTc measured greater than or equal to $480 \mathrm{~ms}$ in an asymptomatic subject or when the calculation of the "probability score" based on clinical criteria, ECG and family history is greater than 3 (2);
- Mutation identified in the patient, regardless of the length of his QTc;

- Patient with a history of syncope with no other cause found, with a QTc greater than or equal to $460 \mathrm{~ms}$, on ECG 12 repeated leads.

It is common to use Bazett's formula to correct the QT value based on heart rate. In our observations, the QT is abnormally long (greater than $500 \mathrm{~ms}$ ). Given the variability of QTc in each individual and even in individuals with congenital long QT syndrome, a probability score has been proposed by Schwartz et al., [3] which also takes into account other ECG abnormalities as well as a personal or family history of malaise.

According to this classification, our patient had a high probability of congenital long QT syndrome.

The introduction of beta-blockers in patients with prolonged QTc is a recommendation for class I, and class IIa for those with normal QTc with an identified mutation.

The recommended beta-blocker is naldolol at a dosage of $1 \mathrm{mg} / \mathrm{kg} / \mathrm{D}$, the protective effect is expected for LQT1 patients and certain LQT2.

For LQT3, the anti-arrhythmic treatment that has demonstrated its effectiveness is mexiletine, a sodium channel blocker at a dosage of $8 \mathrm{mg} / \mathrm{kg} /$ day (4).

The implantable defibrillator finds an indisputable indication in survivors of sudden death (class I) with syncope with beta-blocker (class IIa) and high-risk subjects like SQTL2, SQTL3, and QTc> 500 $\mathrm{ms}$ (class IIb) in the homozygous Jervell and LangeNielsen syndrome, and in symptomatic syncopal SQTL3 or if the QTc exceeds $550 \mathrm{~ms}$.

Survivors of sudden death (class I) with beta blocker syncope (class IIa) and high-risk subjects like SQTL2, SQTL3, and QTc> 500 ms (class IIb) [5-7].

The education of children is an integral part of therapeutic management with advices aiming to avoid any adrenergic stress, any competitive sport (especially for SQTL1), any noise stress (especially SQTL2) and certain drugs liable to prolong the QT or to train torsades de pointes.

\section{Conclusion}

Before of any unexplained discomfort, whether or not linked to the effort, in front of any atypical and unexplained comitiality. The clinician should have the reflex to perform an electrocardiogram and calculate the corrected QT interval. Once the diagnosis is made, exploration of other family members is essential. 
The patient prognosis was transformed by the b-blocker treatment and the implementation of measures to prevent risk factors for torsades de pointes.

\section{REFERENCES}

1. Garson A. The long QT syndrome in children. An international study of 287 patients. Circulation. 1993; 87:1866-72.

2. Morita H, Wu J, Zipes D. The QT syndromes: long and short. The Lancet. 2008; 372:750-63.

3. Schwartz PJ. Diagnostic criteria for the long QT syndrome. An update. Circulation. 1993; 88:782-4.

4. Mazzanti A, Maragna R, Faragli A, Monteforte N, Bloise R, Memmi M, Novelli V, Baiardi P, Bagnardi V, Etheridge SP, Napolitano C. Genespecific therapy with mexiletine reduces arrhythmic events in patients with long QT syndrome type 3. Journal of the American College of Cardiology. 2016 Mar 8;67(9):1053-8.

5. Priori SG, Blomström-Lundqvist C, Mazzanti A, Blom N, Borggrefe M, Camm J, Elliott PM, Fitzsimons D, Hatala R, Hindricks G. 2015 ESC Guidelines for the management of patients with ventricular arrhythmias and the prevention of sudden cardiac death: The Task Force for the Management of Patients with Ventricular Arrhythmias and the Prevention of Sudden
Cardiac Death of the European Society of Cardiology (ESC) Endorsed by: Association for European Paediatric and Congenital Cardiology (AEPC). Ep Europace. 2015 Nov 1;17(11):160187.

6. Priori SG, Wilde AA, Horie M, Cho Y, Behr ER, Berul C, Blom N, Brugada J, Chiang CE, Huikuri H, Kannankeril P. HRS/EHRA/APHRS expert consensus statement on the diagnosis and management of patients with inherited primary arrhythmia syndromes: document endorsed by HRS, EHRA, and APHRS in May 2013 and by ACCF, AHA, PACES, and AEPC in June 2013. Heart rhythm. 2013 Dec 1;10(12):1932-63.

7. Kusumoto FM, Bailey KR, Chaouki AS, Deshmukh AJ, Gautam S, Kim RJ, Kramer DB, Lambrakos LK, Nasser NH, Sorajja D. Systematic review for the $2017 \mathrm{AHA} / \mathrm{ACC} / \mathrm{HRS}$ guideline for management of patients with ventricular arrhythmias and the prevention of sudden cardiac death: a report of the American College of Cardiology/American Heart Association Task Force on Clinical Practice Guidelines and the Heart Rhythm Society. Journal of the American College of Cardiology. 2018 Sep 24;72(14):165376. 